\title{
The Effect of Polyvinylpyrrolidone on the Optical Properties of the Ni-Doped ZnS Nanocrystalline Thin Films Synthesized by Chemical Method
}

\author{
Tran Minh Thi, ${ }^{1}$ Le Van Tinh, ${ }^{1}$ Bui Hong Van, ${ }^{2}$ Pham Van Ben, ${ }^{2}$ and Vu Quoc Trung ${ }^{3}$ \\ ${ }^{1}$ Faculty of Physics, Hanoi National University of Education, 136 Xuan Thuy Road, Cau Giay District, Hanoi, Vietnam \\ ${ }^{2}$ Faculty of Physics, College of Science, Hanoi National University, 334 Nguyen Trai Road, Thanh Xuan District, Hanoi, Vietnam \\ ${ }^{3}$ Faculty of Chemistry, Hanoi National University of Education, 136 Xuan Thuy Road, Cau Giay District, Hanoi, Vietnam
}

Correspondence should be addressed to Tran Minh Thi, tranminhthi@hnue.edu.vn

Received 15 February 2012; Revised 28 March 2012; Accepted 28 March 2012

Academic Editor: Laécio Santos Cavalcante

Copyright () 2012 Tran Minh Thi et al. This is an open access article distributed under the Creative Commons Attribution License, which permits unrestricted use, distribution, and reproduction in any medium, provided the original work is properly cited.

\begin{abstract}
We report the optical properties of polyvinyl-pyrrolidone (PVP) and the influence of PVP concentration on the photoluminescence spectra of the PVP (PL) coated ZnS: Ni nanocrystalline thin films synthesized by the wet chemical method and spin-coating. PL spectra of samples were clearly showed that the $520 \mathrm{~nm}$ luminescence peak position of samples remains unchanged, but their peak intensity changes with PVP concentration. The PVP polymer is emissive with peak maximum at $394 \mathrm{~nm}$ with the exciting wavelength of $325 \mathrm{~nm}$. The photoluminescence exciting (PLE) spectrum of PVP recorded at 394 nm emission shows peak maximum at $332 \mathrm{~nm}$. This excitation band is attributed to the electronic transitions in PVP molecular orbitals. The absorption edges of the PVP-coated ZnS : Ni0.3\% samples that were shifted towards shorter wavelength with increasing of PVP concentration can be explained by the absorption of PVP in range of $350 \mathrm{~nm}$ to $400 \mathrm{~nm}$. While the PVP coating does not affect the microstructure of $\mathrm{ZnS}$ : Ni nanomaterial, the analyzed results of the PL, PLE, and time-resolved PL spectra and luminescence decay curves of the PVP and PVP-coated ZnS: Ni samples allow to explain the energy transition process from surface PVP molecules to the $\mathrm{Ni}^{2+}$ centers that occurs via hot $\mathrm{ZnS}$.
\end{abstract}

\section{Introduction}

Despite intensive research on conductivity, local domain orientation, and molecular order in organic semiconductor thin films [1], the relationship between morphology, chain structure and conductivity of the polymer is still poorly understood. Recently, researchers all over the world have worked on the improvement of electrical conductivity investigated the charge transport and the energy band of a variety of polymers (polyazomethine, aliphatic-aromatic copolyimides). All determined parameters of the electrical conductivity and the energy band have been found to be related to the influence of the polymer chain structure [2-4].

During the last few years there have been extensive experimental and theoretical studies of luminescence, nonlinear optical and electrical properties of a variety of polymers (novel conducting copolymer based on dithienylpyrrole, azobenzene, and EDOT units) in the direction of material science as electronic devices and displays $[2,3,5-8]$. New progress has been made in the area of thermoelectric (TE) applications of conducting polymers and related organicinorganic composites $[9,10]$. Other research efforts aimed to identify the role of additives in optimizing the morphology of organic solar cells and discussed the role of bimolecular recombination in limiting the efficiency of solar cells based on a small optical gap polymer $[11,12]$.

Recently, methods have been developed to cap the surfaces of the nanoparticles with organic or inorganic groups so that the nanoparticles are stable against agglomeration. Among the inorganic semiconductor nanoparticles, zinc sulfide $\mathrm{ZnS}$ is an important II-VI semiconductor, which has been studied extensively because of its broad spectrum of 
potential applications, such as in catalysis and electronic and optoelectronic nanodevices. Furthermore, luminescent properties of $\mathrm{ZnS}$ can be controlled using various dopants such as $\mathrm{Ni}, \mathrm{Fe}, \mathrm{Mn}$, and $\mathrm{Cu}$ [13-19]. They not only give luminescence in various spectral regions but also enhance the excellent properties of $\mathrm{ZnS}$. In order to cap the $\mathrm{ZnS}$ nanoparticles, some particular passivators of $\mathrm{ZnS}$ have been used, such as polyvinyl alcohol (PVA) [20] and polyvinylpyrrolidone (PVP) [21-25]. Understanding the effect of capping on nanoparticles is one of the most important topics nowadays. The influence of surface passivation on luminescence quantum efficiency of $\mathrm{ZnS}: \mathrm{Mn}^{2+}$ and $\mathrm{ZnS}: \mathrm{Cu}^{2+}$ nanoparticles has been discussed when using sodium hexametaphosphate (SHMP), PVP and PVA as coating agents [2628]. However, till now, there are only a few papers focused on investigation of the optical properties of PVP-coated $\mathrm{ZnS}$ nanocomposite materials and the process of energy transfer from organic surface adsorbate of PVP to the dopant ions $\left(\mathrm{Cu}^{2+}, \mathrm{Mn}^{2+}\right)$. Furthermore, there are not any papers completely investigating the optical properties of PVP-coated $\mathrm{ZnS}$ : Ni nanocomposite materials.

Thus, in this paper we report the optical properties of PVP (polyvinyl-pyrrolidone) and the influence of PVP concentration on the PL spectra of the PVP-coated $\mathrm{ZnS}: \mathrm{Ni}$ nanocrystalline thin films synthesized by the wet chemical method and spin-coating. Further, the influences of PVP concentration on the general features of the PL spectra and the process of energy transfer from the PVP to the $\mathrm{Ni}^{2+}$ luminescent centers in doped $\mathrm{ZnS}$ as well as the optical band gap variation are also discussed.

\section{Experiments}

2.1. Preparation of ZnS: Ni Nanopowders. The polymer polyvinyl-pyrrolidone and initial chemical substances with high purity (99.9\%) (Merck chemicals) were prepared as follows:

Solution I: $0.1 \mathrm{M} \mathrm{Zn}\left(\mathrm{CH}_{3} \mathrm{COO}\right)_{2}$ in water,

Solution II: $0.1 \mathrm{M} \mathrm{NiSO}_{4}$ in water,

Solution III: $0.1 \mathrm{M} \mathrm{Na}_{2} \mathrm{~S}$ in water,

Solution IV: $\mathrm{CH}_{3} \mathrm{OH}: \mathrm{H}_{2} \mathrm{O}(1: 1)$.

Firstly, ZnS : Ni nanoparticles were synthesized by the wet chemical method. Solutions I, II, and III were mixed at an optimal $\mathrm{pH}=4.5$ and in an appropriate ratio in order to create Ni-doped $\mathrm{ZnS}$ powder materials with different molar ratios of $\mathrm{Ni}^{2+}$ and $\mathrm{Zn}^{2+}$ as follows: $0.0 \%, 0.2 \%, 0.3 \%, 0.6 \%$, and $1 \%$. The precipitated $\mathrm{ZnS}$ nad $\mathrm{NiS}$ nanoparticles were formed by stirring of the mixed solutions at $80^{\circ} \mathrm{C}$ for 30 minutes following the chemical reactions

$$
\begin{gathered}
\mathrm{Zn}\left(\mathrm{CH}_{3} \mathrm{COO}\right)_{2}+\mathrm{Na}_{2} \mathrm{~S} \longrightarrow \mathrm{ZnS}+2 \mathrm{CH}_{3} \mathrm{COONa} \\
\mathrm{NiSO}_{4}+\mathrm{Na}_{2} \mathrm{~S} \longrightarrow \mathrm{NiS}+\mathrm{Na}_{2} \mathrm{SO}_{4}
\end{gathered}
$$

These precipitated $\mathrm{ZnS}$ and NiS nanoparticles were filtered by filtering system and then washed in distilled water and ethanol several times. Finally, they were dried under nitrogen gas for $6 \mathrm{~h}$ at $60^{\circ} \mathrm{C}$. These powder samples were named $\mathrm{ZnS}$, $\mathrm{ZnS}: \mathrm{Ni} 0.2 \%, \mathrm{ZnS}: \mathrm{Ni} 0.3 \%$, ZnS : Ni0.6\%, and ZnS: Ni1\%, corresponding to different molar ratios of $0.0 \%, 0.2 \%, 0.3 \%$, $0.6 \%$, and $1 \%$ of $\mathrm{Ni}^{2+}$ and $\mathrm{Zn}^{2+}$.
2.2. Preparation of Thin Films and Powders from PVP-Capped $Z n S$ : Ni Nanocrystals. In order to study the role and the effect of PVP on the optical properties of $\mathrm{ZnS}: \mathrm{Ni}$, the PVP coated $\mathrm{ZnS}$ : Ni nanoparticles were synthesized by keeping a constant nominal Ni concentration of $0.3 \%$, but variation of polymer concentrations.

\subsubsection{Preparation of Thin Films from PVP Capped ZnS: Ni} Nanocrystals. After washing, $0.1 \mathrm{~g}$ formed $\mathrm{ZnS}: \mathrm{Ni} 0.3 \%$ precipitates were dispersed into $10 \mathrm{~mL}$ of $\mathrm{CH}_{3} \mathrm{OH}: \mathrm{H}_{2} \mathrm{O}(1: 1)$ solvent. This mixture was called solution IV. Similarly, $0.1 \mathrm{~g}$ of PVP was dissolved in $10 \mathrm{~mL}$ of $\mathrm{CH}_{3} \mathrm{OH}: \mathrm{H}_{2} \mathrm{O}(1: 1)$ solvent and was called solution V. After that these two solutions IV and $\mathrm{V}$ were mixed with each other at various volume ratios of $(5: 0),(5: 1),(5: 2),(5: 3),(5: 4)$, and $(5: 7)$ under continuous stirring for $1 \mathrm{~h}$ at speed of $3000 \mathrm{rpm}$.

The thin films $\operatorname{M-PVP}(5: 0)$, M-PVP(5:1), M$\operatorname{PVP}(5: 2), \operatorname{M-PVP}(5: 3)$, and $\mathrm{M}-\mathrm{PVP}(5: 4)$ were produced by the spin-coating method on glass substrate using the rotation speed of $1500 \mathrm{rpm}$ with the same drop-by-drop method and dried at $60^{\circ} \mathrm{C}$ for all samples.

\subsubsection{Preparation of Powders from PVP-Capped ZnS: Ni Na-} nocrystals. In order to receive the PVP coated $\mathrm{ZnS}: \mathrm{Ni} 0.3 \%$ nanopowders with different PVP concentrations, the mixed solutions of IV and V were centrifuged at speed $3000 \mathrm{rpm}$. Then, the received PVP-coated $\mathrm{ZnS}: \mathrm{Ni} 0.3 \%$ nanoparticles were dried at $80^{\circ} \mathrm{C}$. These PVP coated $\mathrm{ZnS}: \mathrm{Ni} 0.3 \%$ nanopowders are named $\mathrm{B}(5: 0), \mathrm{B}(5: 1), \mathrm{B}(5: 2), \mathrm{B}(5: 3)$, $\mathrm{B}(5: 4)$ and $\mathrm{B}(5: 7)$.

2.3. Research Methods. The microstructure of these samples was investigated by X-ray diffraction (XRD) using XD8 Advance Bruker Diffractometer with $\mathrm{CuK}_{\alpha}$ radiation of $\lambda=1.5406 \AA$ and high-resolution transmission electron microscope (HR-TEM). Photoluminescence (PL) spectra, photoluminescence exciting (PLE) spectra, and the absorption spectra of these samples at room temperature were recorded by Fluorolog FL3-22, HP340-LP370 Fluorescence Spectrophotometer with an excitation wavelength of $325 \mathrm{~nm}$, $337 \mathrm{~nm}$, xenon lamp XFOR-450, and JASCO-V670 spectrophotometer, respectively. The time-resoled PL spectra of samples were measured by GDM-100 spectrophotometer using Boxca technique.

\section{Results and Discussion}

3.1. Analysis of Microstructure by XRD Patterns, Atomic Absorption Spectroscopy, and TEM. Figure 1 shows X-ray diffraction spectra of the pure $\mathrm{ZnS}$ nanopowders (inset), $\mathrm{ZnS}: \mathrm{Ni0.3 \%}$ with different PVP concentration, B(5:0), $\mathrm{B}(5: 1), \mathrm{B}(5: 4)$, corresponding to curves $\mathrm{a}, \mathrm{b}$, and $\mathrm{c}$. The analyzed results show that all samples have a sphalerite structure. The three diffraction peaks of $2 \theta=28.8^{\circ}, 48.1^{\circ}$, and $56.5^{\circ}$ with strong intensity correspond to the (111), (220), and (311) planes. It is shown that the PVP polymer does not affect the microstructure of $\mathrm{ZnS}$ : Ni nanomaterials. Thus, one can point out that the PVP coating on the surface 


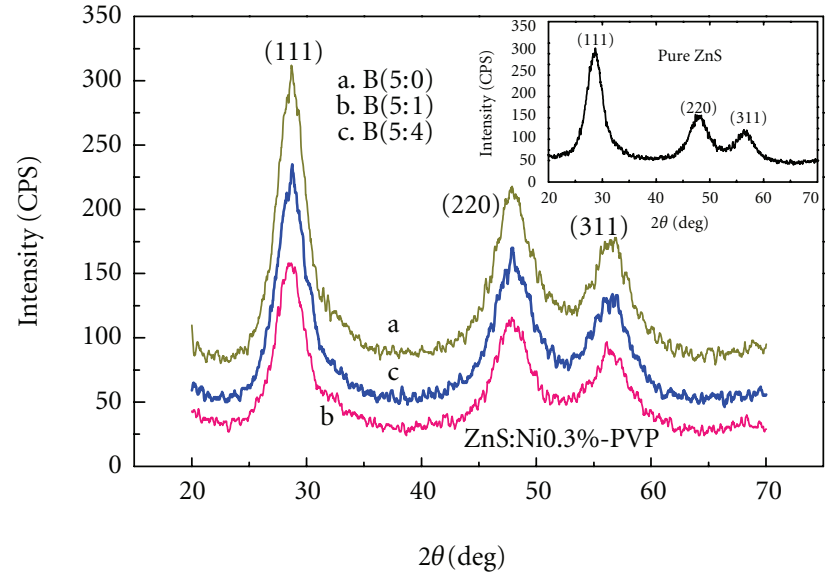

Figure 1: The X-ray diffraction spectra of samples $\mathrm{B}(5: 0) ; \mathrm{B}(5: 1)$; $\mathrm{B}(5: 4)$ - curves a, b, c, and respectively — and pure $\mathrm{ZnS}$ nanopowders (inset).

TABle 1: The band gap of PVP, B(5:0), B(5:1), B(5:2), B(5:3), $\mathrm{B}(5: 4)$, and $\mathrm{B}(5: 7)$ samples with different PVP concentrations.

\begin{tabular}{lccc}
\hline No. & Sample & $E_{g}(\mathrm{eV})$ & Grain size $(\mathrm{nm})$ \\
\hline 1 & $\mathrm{~B}(5: 0)$ & 3.11 & 2,4 \\
2 & $\mathrm{~B}(5: 1)$ & 3.19 & 2,4 \\
3 & $\mathrm{~B}(5: 2)$ & 3.24 & \\
4 & $\mathrm{~B}(5: 3)$ & 3.28 & 2,5 \\
5 & $\mathrm{~B}(5: 4)$ & 3.29 & \\
6 & $\mathrm{~B}(5: 7)$ & 3.43 & \\
7 & PVP & 4.19 & \\
\hline
\end{tabular}

of $\mathrm{ZnS}: \mathrm{Ni}$ nanoparticles possesses the same structure as the amorphous shells (in Figure 2(a)). From the diffraction peaks of $2 \theta$ and the standard Bragg relation, the interplanar distance $d=3.12 \AA$ and then the lattice constant $a=$ $5.4 \AA$ for the cubic phase were calculated by the following equations:

$$
2 d \sin \theta=n \lambda, \quad \frac{1}{d^{2}}=\frac{h^{2}+k^{2}+l^{2}}{a^{2}},
$$

where $d$ is the interplanar distance and $h, k$, and $l$ denote the lattice planes.

The average size of the Ni-doped $\mathrm{ZnS}$ grains is about $2-3 \mathrm{~nm}$, was calculated by which the Scherrer formula (in Table 1).

Figure 2(b) gives the molecular structure and formula of polyvinyl-pyrrolidone (PVP) with both $\mathrm{N}$ and $\mathrm{C}=\mathrm{O}$ groups. In PVP, nitrogen is conjugated with adjacent carbonyl groups. Thus, the role of PVP consists of (a) forming passivating layers around the $\mathrm{ZnS}$ : $\mathrm{Ni}$ core due to coordination bond formation between the nitrogen atom of PVP and $\mathrm{Zn}^{2+}$ and (b) preventing agglomeration of the particles by the repulsive force acting among the polyvinyl groups [23].

Figure 3(a) presents the HR-TEM image of $\mathrm{B}(5: 3)$ sample. Figure 3(b) demonstrates the distributions of the adjacent interplanar distances of (111) planes corresponding to Figure 3(a) (inset). From Figure 3(b) the adjacent interplanar distance of (111) planes is about 3.13 $\AA$. This result is suitable for the XRD patterns and proves that the crystalline is obtained in the as-synthesized samples $\mathrm{ZnS}$ : Ni-PVP.

3.2. Photoluminescence Spectra Measurements. Figure 4 shows the photoluminescence PL spectra with the exciting wavelength of $325 \mathrm{~nm}$ of the $\mathrm{ZnS}: \mathrm{Ni0} .2 \%, \mathrm{ZnS}: \mathrm{Ni0.3 \%}$ $\mathrm{ZnS}: \mathrm{Ni} 0.6 \%$, ZnS:Ni1.0\%, and ZnS powder samples, corresponding to curves $\mathrm{a}, \mathrm{b}, \mathrm{c}, \mathrm{d}$, and e. The peak maximum of $\mathrm{ZnS}$ is about $450 \mathrm{~nm}$, meanwhile the PL spectra of $\mathrm{ZnS}: \mathrm{Ni0.2 \%}$, ZnS : Ni0.3\% ZnS : Ni0.6\%, and ZnS : Ni1.0\% samples show peak maximum at $520 \mathrm{~nm}$. In order to study the influence of $\mathrm{Ni}$ concentration on photoluminescence of samples, all measured parameters (such as temperature, sample volume, and exciting wavelength intensity) were kept constant for every measurement of samples. This clearly shows that the luminescence peak maximum positions of $\mathrm{ZnS}: \mathrm{Ni}$ samples are unchanged, but their intensities change rather strongly with increasing of PVP concentration. One of these samples with the large luminescence intensity is $\mathrm{ZnS}: \mathrm{Ni} 0.3 \%$ sample. The relative luminescence intensity of this sample is also about double of that of the pure $\mathrm{ZnS}$ sample. In comparison with other results, this result also agrees with previous works $[13,15]$, in which the samples were synthesized from initial chemicals: $\mathrm{Zn}\left(\mathrm{CH}_{3} \mathrm{COO}\right)_{2} \cdot 2 \mathrm{H}_{2} \mathrm{O}, \mathrm{NiSO}_{4}$, and TAA $\left(\mathrm{C}_{2} \mathrm{H}_{5} \mathrm{NS}\right)$. The blue emission band of pure $\mathrm{ZnS}$ sample is attributable to the intrinsic emission of defects, vacancy, and an incorporation of trapped electron by defects at donor level under conduction range when the dopant-Ni was added into the hot $\mathrm{ZnS}$ semiconductor. Moreover, due to the energy levels of $\mathrm{Ni}^{2+}\left(\mathrm{d}^{8}\right)$ in $\mathrm{ZnS}$ semiconductor materials, the lowest multiplex term ${ }^{3} \mathrm{~F}$ of the free $\mathrm{Ni}^{2+}$ ion is split into ${ }^{3} \mathrm{~T}_{1},{ }^{3} \mathrm{~T}_{2}$, and ${ }^{3} \mathrm{~A}_{2}$ through the anisotropic hybridization $[13,15]$. Thus, the green luminescence of about $520 \mathrm{~nm}$ is attributed to the $\mathrm{d}-\mathrm{d}$ optical transitions of $\mathrm{Ni}^{2+}$, and the luminescent center of $\mathrm{Ni}^{2+}$ is formed in $\mathrm{ZnS}$.

In order to observe the influence of PVP concentration on optical properties of samples, the $\operatorname{M-PVP}(5: 0)$, M$\operatorname{PVP}(5: 1), \operatorname{M-PVP}(5: 2), \operatorname{M-PVP}(5: 3)$, and $\operatorname{M-PVP}(5: 4)$ thin films were measured by the photoluminescence PL spectra using the exciting wavelength of $325 \mathrm{~nm}$ (in Figure 5). It is clearly shown that these luminescence peak positions of samples remain unchanged but their peak intensities increase with increasing of PVP concentration from $(5: 0)$ to $(5: 4)$.

These results show that PVP does not affect the microstructure of $\mathrm{ZnS}: \mathrm{Ni}$ but plays an important role to improve the optical properties of $\mathrm{ZnS}$ : Ni nanoparticles.

3.3. Absorption Spectra and Photoluminescence Excitation (PLE) Spectra. The absorption spectra of PVP sample and the $\mathrm{B}(5: 0), \mathrm{B}(5: 1), \mathrm{B}(5: 2), \mathrm{B}(5: 3), \mathrm{B}(5: 4)$, and $\mathrm{B}(5: 7)$ samples (PVP-coated ZnS: Ni0.3\% samples with different PVP concentrations) are shown in Figure 6.

It is known that the light transition through the environment can be demonstrated by the Beer-Lambert law:

$$
I(\nu)=I_{0}(\nu) \cdot e^{-\alpha(\nu) d},
$$




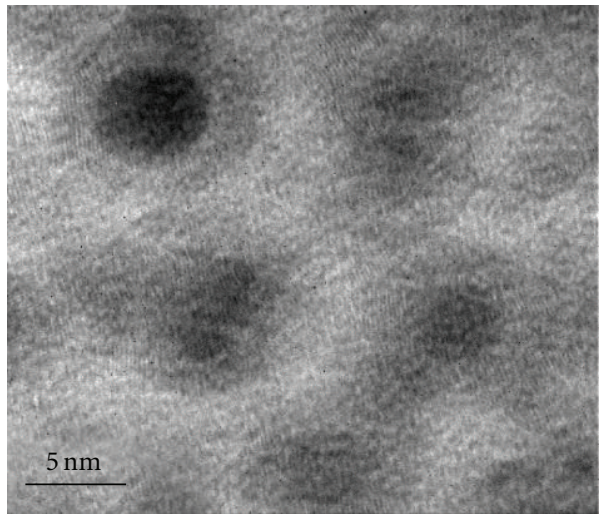

(a)

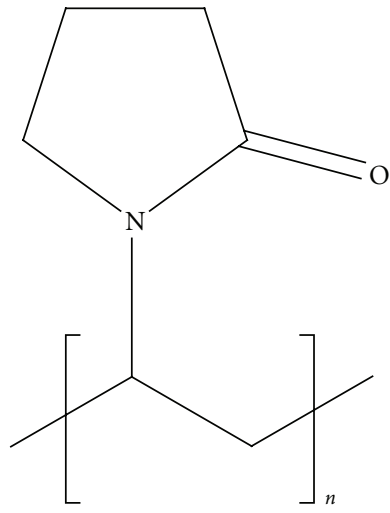

(b)

Figure 2: (a) HR-TEM image of $\mathrm{B}(5: 3)$ sample. (b) The structure and formula of polyvinyl-pyrrolidone $\left(\mathrm{C}_{6} \mathrm{H}_{9} \mathrm{NO}\right)_{n}$.

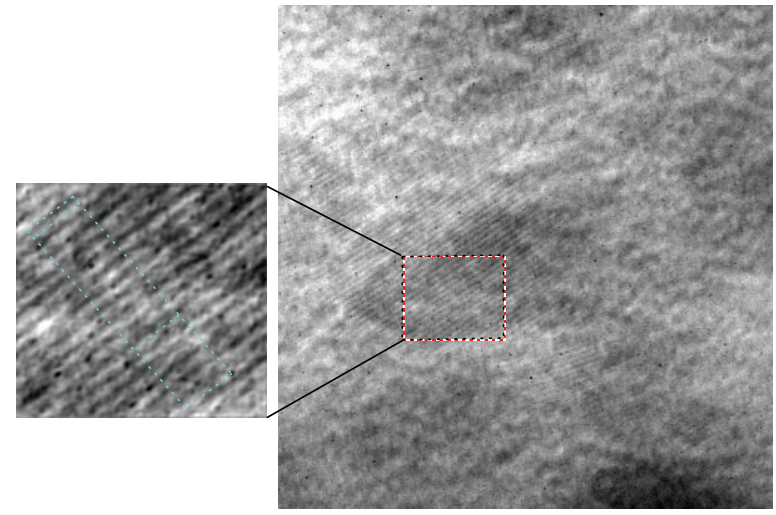

(a)

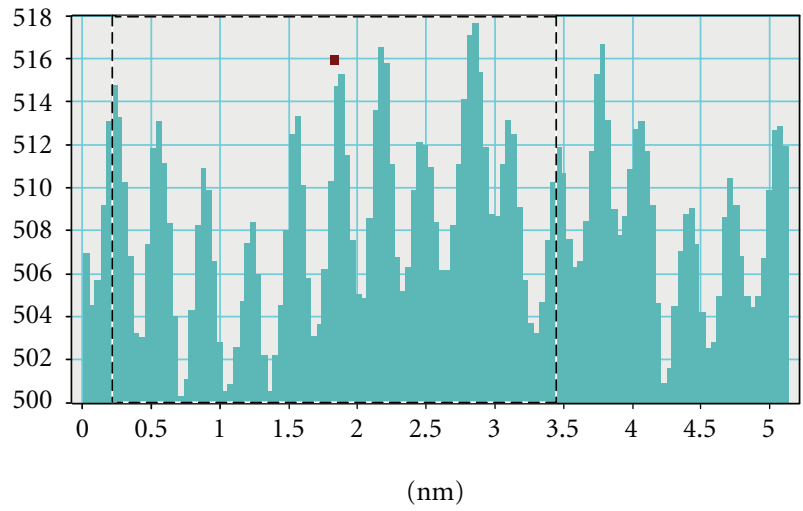

(b)

FIgURE 3: (a) HR-TEM image of B(5:3) sample. (b) The interplanar distances of (111) planes.

where $I_{0}(\nu)$ and $I(\nu)$ are intensities of light in front of and behind the environment, $\alpha(v)$ is absorption coefficient of this environment relative to photon with energy $h v$, and $d$ is the thickness of the film.

Formula (3) can be rewritten in logarithmic form:

$$
\alpha(\nu) \cdot d=\ln \frac{I_{0}(\nu)}{I(\nu)}=\ln 10 \cdot \lg \frac{I_{0}(\nu)}{I(\nu)}=2.3 \cdot A \quad \text { or } \alpha=\frac{2.3 A}{d},
$$

with $A=\lg \left(I_{0}(\nu) / I(\nu)\right)$ being the absorption.

The relation between absorption coefficient $\alpha$ and energy of photon was represented by the following equation [22]:

$$
\alpha=\frac{K\left(h v-E_{g}\right)^{n / 2}}{h v}
$$

where $K$ is a constant, $E_{g}$ is the band gap of material, the exponent $n$ is dependent on the type of transition (here, $n=$ 1 for the direct transition of $\mathrm{ZnS}$ : Ni semiconductor).

From (4) and (5), it can be written as

$$
(A h \nu)^{2}=B\left(h v-E_{g}\right), \quad \text { where } B \text { is constant. }
$$

By (6), the absorption spectra of samples are converted into the plots of $(A h v)^{2}$ versus $h v$ (Figure 6 inset). The values of the band gap $E_{g}$ were determined by extrapolating the straight line portion of the $(A h v)^{2}$ versus $h v$ graphs to the $h \nu$-axis (Figure 6 inset). Table 1 gives the band gap values of PVP and the $\mathrm{B}(5: 0), \mathrm{B}(5: 1), \mathrm{B}(5: 2), \mathrm{B}(5: 3), \mathrm{B}(5: 4)$, and $B(5: 7)$ samples, calculated from these absorption spectra. It is clear that the band gap of the $\mathrm{B}(5: 0)$ sample $(\mathrm{ZnS}: \mathrm{Ni} 0.3 \%$ sample) is smaller in comparison with that of pure $\mathrm{ZnS}$ $(3.68 \mathrm{eV})$. This decreasing is possibly attributed to the bandedge tail constitution of state density in band gap, by the s$\mathrm{d}$ exchange interaction between $3 \mathrm{~d}^{8}$ electrons of $\mathrm{Ni}^{2+}$ and $\mathrm{s}$ conduction electrons in $\mathrm{ZnS}$ crystal $[29,30]$. On the contrary to this issue of $\mathrm{ZnS}: \mathrm{Ni}$ (in comparison with that of pure $\mathrm{ZnS}$ ), the band gap of the PVP-coated $\mathrm{ZnS}: \mathrm{Ni}$ samples increases from $3.11 \mathrm{eV}$ to $3.43 \mathrm{eV}$ with the increasing of PVP concentration (the absorption spectra shifted toward shorter wavelength).

Because $\mathrm{ZnS}$ : Ni nanoparticles were formed in preparation process before they dispersed into PVP matrix, therefore, PVP do not effect to size of nanoparticles. However, the PVP play an important role as the protective layer, against agglomeration $\mathrm{ZnS}: \mathrm{Ni}$ nanoparticles and contribute to 


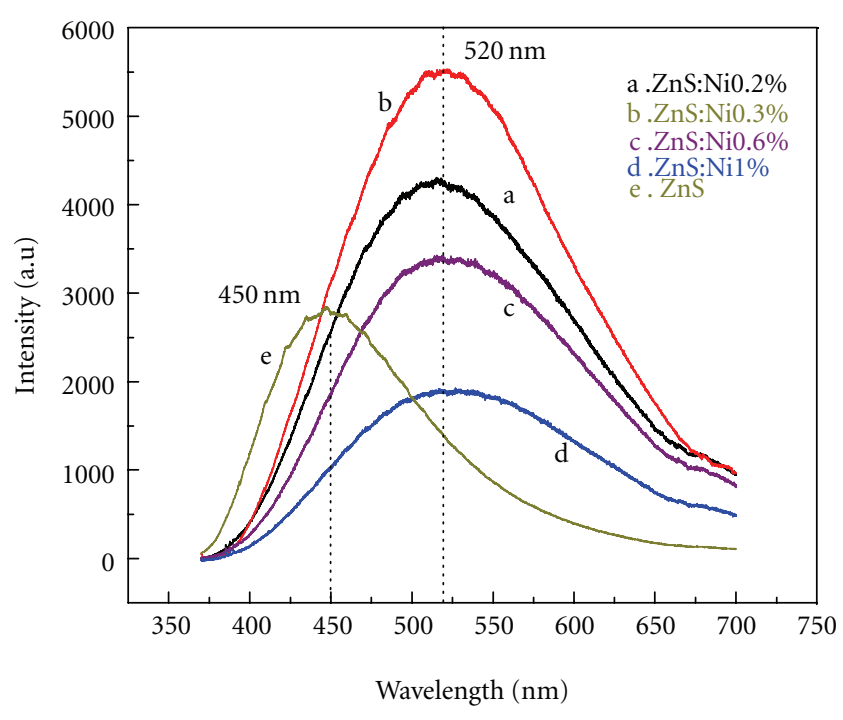

Figure 4: PL spectra of powder samples.

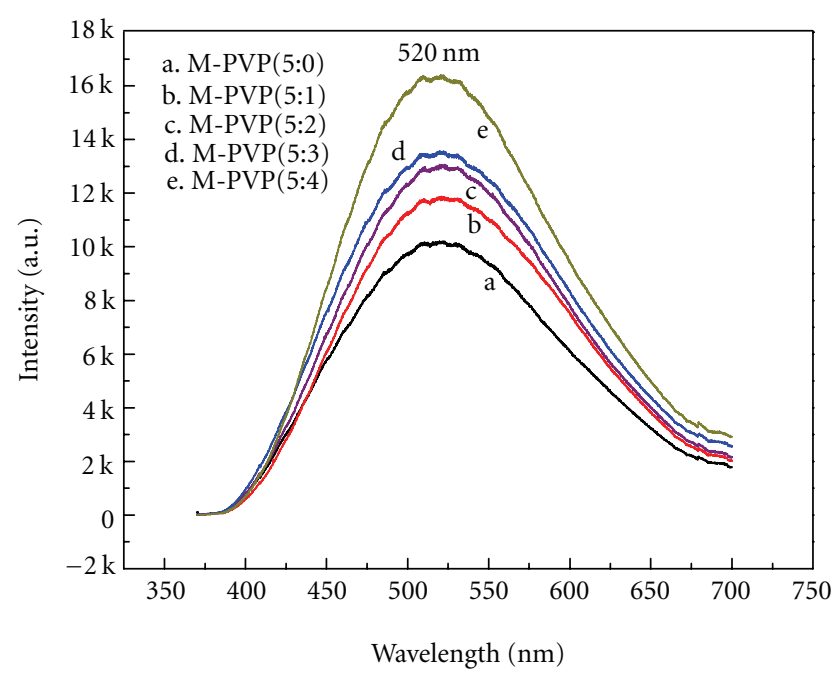

Figure 5: PL spectra of thin films.

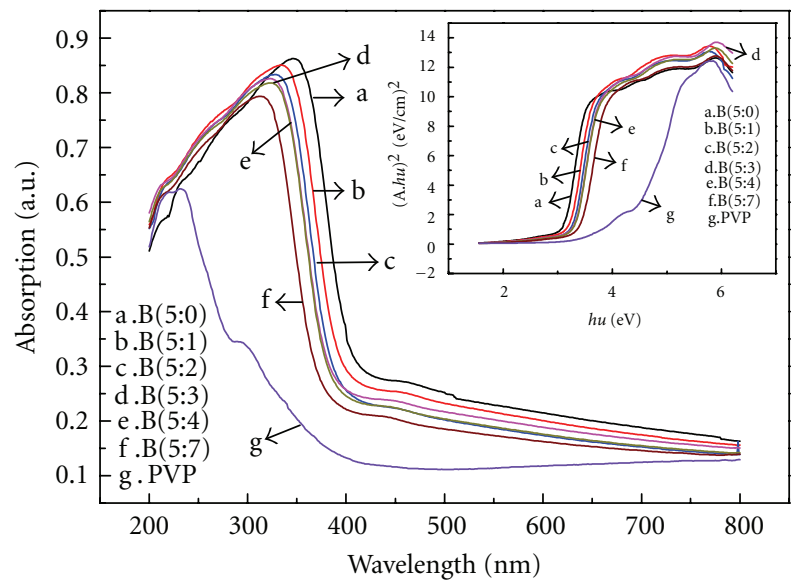

Figure 6: The absorption spectra of PVP, B(5:0), B(5:1), B(5:2), $\mathrm{B}(5: 3), \mathrm{B}(5: 4)$, and $\mathrm{B}(5: 7)$ samples. The plots of $(A h \nu)^{2}$ versus $h \nu$ (inset).

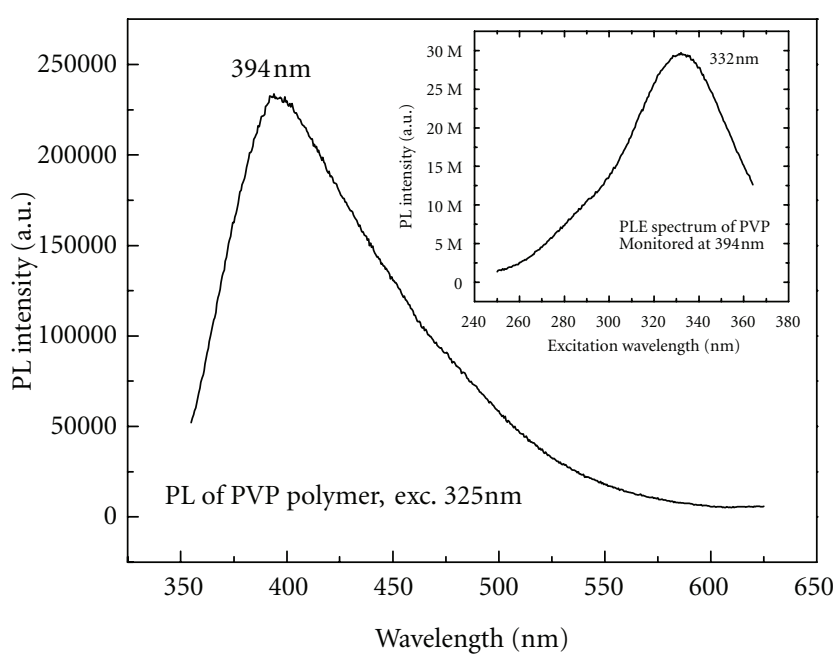

FIGURE 7: PL spectra and PL excitation (PLE) spectra of PVP (inset).

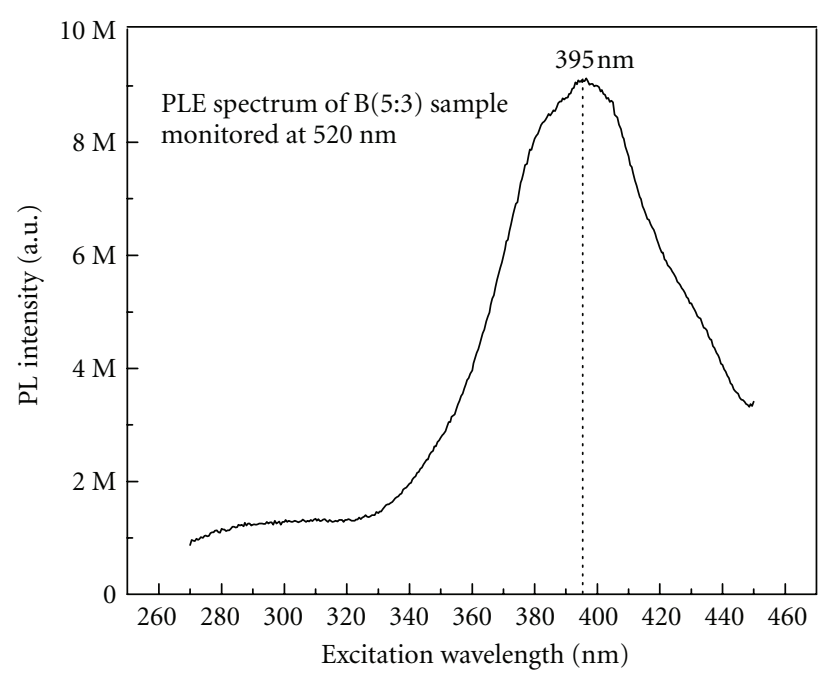

Figure 8: The PLE band of $\mathrm{B}(5: 3)$ monitored at $520 \mathrm{~nm}$.

increase optical properties of $\mathrm{ZnS}$ : Ni nanoparticles. The absorption edge and right shoulder of PVP in the range from $230 \mathrm{~nm}$ to $400 \mathrm{~nm}$ and the absorption edges and right shoulders of PVP-coated $\mathrm{ZnS}: \mathrm{Ni} 0.3 \%$ samples in range from $350 \mathrm{~nm}$ to $400 \mathrm{~nm}$ showed clearly the shift toward to short wavelength with increasing of PVP concentration. Due to the PVP absorption the photons in wavelength range from $230 \mathrm{~nm}$ to $400 \mathrm{~nm}$, and thus the blue shift of the absorption edge in the range from $350 \mathrm{~nm}$ to $400 \mathrm{~nm}$ can be explained by increasing of PVP concentration of the PVPcoated $\mathrm{ZnS}: \mathrm{Ni0}$ \% $\%$ samples.

In order to examine the process of energy transfer in the PVP-coated ZnS: Ni nanoparticles, the PVP and B $(5: 3)$ samples were measured by the PL, the PLE spectra as in Figures 7 and 8 , respectively. It is interesting to see that the PVP is emissive with peak maximum at $394 \mathrm{~nm}$ with the exciting wavelength of $325 \mathrm{~nm}$. Simultaneously, the PLE spectrum recorded at $394 \mathrm{~nm}$ emission of PVP shows peak maximum at $332 \mathrm{~nm}$ in Figure 7 (inset). This excitation 


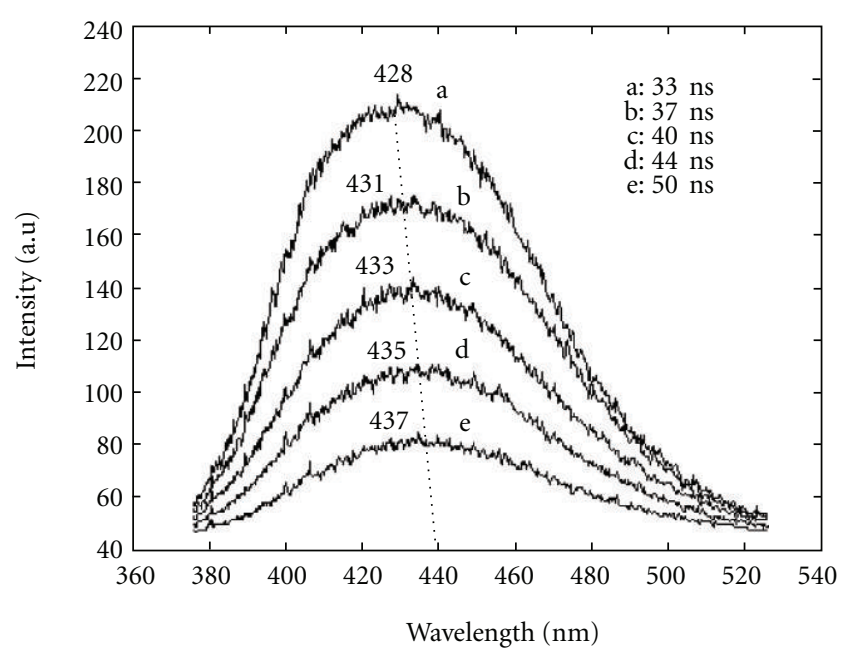

FIGURE 9: The time-resolved PL spectra of PVP at $300 \mathrm{~K}$ excited by pulse $\mathrm{N}_{2}$ laser with $337 \mathrm{~nm}$ wavelength, pulse width of $7 \mathrm{~ns}$, and frequency of $10 \mathrm{~Hz}$. The delay times after the excitation pulse are $33 \mathrm{~ns}$, $37 \mathrm{~ns}, 40 \mathrm{~ns}, 44 \mathrm{~ns}$, and $50 \mathrm{~ns}$, respectively.

band is attributed to the electronic transitions in PVP molecular orbitals. Alternatively, the blue emission band of PVP at $394 \mathrm{~nm}$ is attributed to the radiative relaxation of electrons from the lowest energy unoccupied molecular orbital (LUMO) to the highest energy occupied molecular orbital (HOMO) levels in PVP [31]. As seen in Figure 7 (inset), the PLE band of PVP monitored at $394 \mathrm{~nm}$ has a peak maximum at $332 \mathrm{~nm}$, while the PLE band of $\mathrm{B}(5: 3)$ monitored at $520 \mathrm{~nm}$ (Figure 8) shows a peak maximum at $395 \mathrm{~nm}$. These results show that the PL peak of $394 \mathrm{~nm}$ of PVP sample coincided exactly with the PLE peak of $\mathrm{B}(5: 3)$ sample. Thus, the exciting wavelength of $325 \mathrm{~nm}$ is becoming the luminescent emission at $520 \mathrm{~nm}$ of the PVPcoated ZnS:Ni samples. From above analysed results of PLE spectra of PVP, $\mathrm{B}(5: 3)$ samples and the PL spectra of the sample systems (Figures 4 and 5) with the exciting wavelength of $325 \mathrm{~nm}$, it is reasonable to suppose that (i) the high energy band in the PLE spectrum of ZnS : Ni-PVP arises from the surface PVP molecules, (ii) the energy transfer occurs between the energy levels of surface PVP molecular orbitals and the luminescence centers of $\mathrm{ZnS}: \mathrm{Ni}$, and (iii) the energy transition from surface PVP molecules to the $\mathrm{Ni}^{2+}$ centers occurs via hot $\mathrm{ZnS}$.

\subsection{Time-Resolved PL Spectra and Luminescence Decay} Curves. The investigation of the kinetic decay process of electrons in energy bands is very important to the study of luminescence. It can provide a scientific basis for the improvement of the luminescence efficiency of optical materials. Figure 8 shows the time-resolved PL spectra of PVP at $300 \mathrm{~K}$ excited by pulse $\mathrm{N}_{2}$ laser with $337 \mathrm{~nm}$ wavelength, pulse width of $7 \mathrm{~ns}$, and frequency of $10 \mathrm{~Hz}$. These peaks of these spectra are shifted toward longer wavelength from $428 \mathrm{~nm}$ to $437 \mathrm{~nm}$ with increasing of the delay time from 33 ns to 50 ns. It shows clearly that these peaks belong to the right shoulder in range of $390-470 \mathrm{~nm}$ of PL spectrum

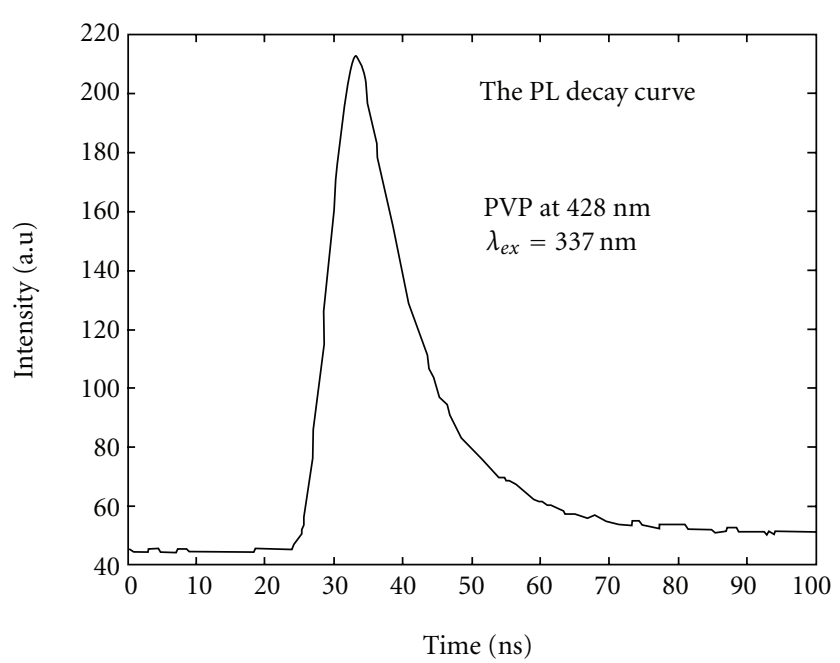

FIgure 10: The PL decay curve of PVP.

of PVP excited by laser wavelength of $325 \mathrm{~nm}$ (in Figure 7). Beside that, Figure 9 also shows that the PL peak intensity decreases while the spectral width of the PL band (full-width at half-maximum) decrease with increasing of the delay time. These PL properties are attributed to electron transition from LUMO to HOMO levels in PVP molecules.

Figure 10 shows the PL decay curve of PVP at $428 \mathrm{~nm}$ when using exciting wavelengths $337 \mathrm{~nm}$. The decay curve shows that the number of free photoelectrons in exciting energy bands (corresponding to $428 \mathrm{~nm}$ wavelength) is decreased by exponential attenuation and is given by $n \propto e^{-t / \tau}$, where $\tau$ is the lifetime of electrons in exciting energy band. From this PL decay curve, the lifetime of free photoelectrons is calculated as $\tau=15.5 \mathrm{~ns}$ for PVP at $428 \mathrm{~nm}$. The lifetime $\tau$ is shorter than that in $\mathrm{ZnS}: \mathrm{Mn}, \mathrm{Cu}$ samples sintered at high temperatures [32]. On the other hand, the lifetime $\tau$ is very short, thus it is characteristic of the radiative relaxation of electrons from the lowest energy unoccupied molecular orbital (LUMO) to the highest energy occupied molecular orbital (HOMO) levels in PVP. From the above analyzed results of PVP, the blue luminescence of PVP may be attributed to the radiative relaxation of electrons from LUMO to HOMO levels as in Figure 12.

3.5. On the Energy Transfer from Surface PVP Molecules to the $\mathrm{Ni}^{2+}$ Centers. The PVP is a conjugated polymer with both $\mathrm{N}$ and $\mathrm{C}=\mathrm{O}$ groups. So with the $\mathrm{ZnS}$ : Ni-PVP samples, it is believed that the bond between metal ions and PVP can give rise to overlapping of molecular orbitals of PVP with atomic orbitals of metal ions in surface regions $[23,31]$. Thus, from the above results, we believe that the PVP passivating layers around the $\mathrm{ZnS}$ : Ni core described in Figure 11 are formed by coordination bond between the nitrogen atom of PVP and $\mathrm{Zn}^{2+}$ [31]. Figure 11 shows the incomplete coverage with low concentration of PVP (Figure 11(a)) and the complete coverage with higher concentration of PVP (Figure 11(b)). 


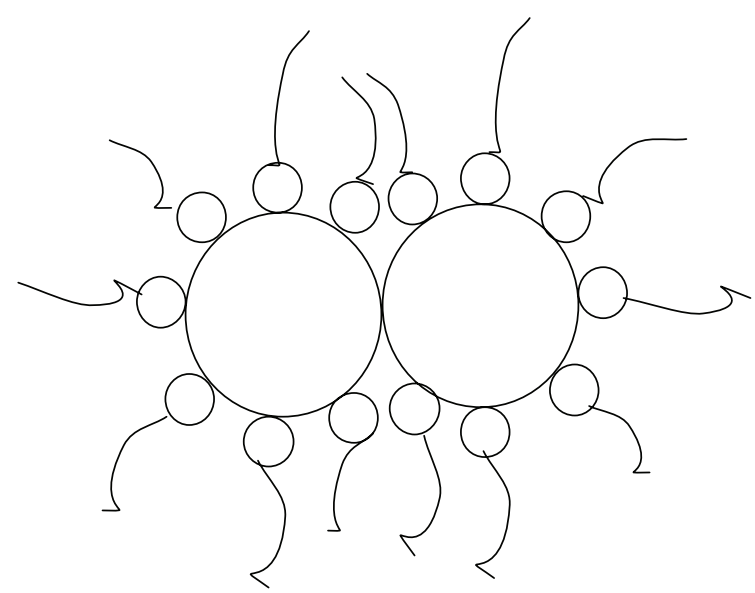

(a) Incomplete coverage

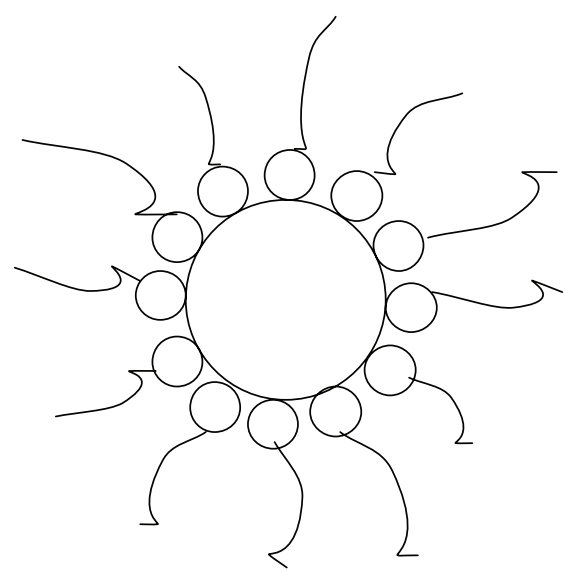

(b) Complete coverage

FIgURE 11: The PVP coverage of ZnS : Ni grains.

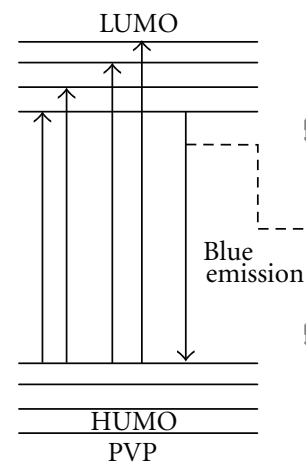

(a) Blue emitssion by
electronic transitions
from LUMO to HOMO

FIGURE 12: Schematic illustration of various electronic transition and energy transfer processes in ZnS: Ni-PVP.

It is clear from these above analyzed results of the PL spectra, PLE spectra, time-resolved PL spectra, and luminescence decay curves of PVP and PVP-coated ZnS : Ni samples that the energy transition process from surface PVP molecules to the $\mathrm{Ni}^{2+}$ centers occurs via hot $\mathrm{ZnS}$ illustrated as in Figures 12(a) and 12(b).

\section{Conlusion}

From the above experimental results, the influence of surface passivation on the luminescence intensity of $\mathrm{ZnS}: \mathrm{Ni}$ nanoparticles has been observed due to efficient energy transfer from the surface PVP molecules to the $\mathrm{Ni}^{2+}$ centers in $\mathrm{ZnS}: \mathrm{Ni}$ nanoparticles. With increasing the PVP concentration, the absorption edge of the PVP-coated ZnS: Ni nanoparticles shows the blue shift, which is explained due to the influence of PVP concentration on the shift of the absorption spectra.

\section{Acknowledgment}

This work was supported by Vietnam's National Foundation for Science and Technology Development (NAFOSTED) (Code 103.02.2010.20).

\section{References}

[1] C. R. McNeill, "Imaging the domain structure of organic semiconductor films," Journal of Polymer Science B, vol. 49, no. 13, pp. 909-919, 2011.

[2] B. Jarzabek, J. Weszka, M. Domański, J. Jurusik, and J. Cisowski, "Optical studies of aromatic polyazomethine thin films," Journal of Non-Crystalline Solids, vol. 354, no. 10-11, pp. 856-862, 2008.

[3] B. Jarzabek, J. Weszka, M. Domanski, J. Jurusik, and J. Cisowski, "Optical properties of amorphous polyazomethine thin films," Journal of Non-Crystalline Solids, vol. 352, no. 920, pp. 1660-1662, 2006.

[4] B. Jarzabek, E. Schab-Balcerzak, T. Chamenko, D. Sek, J. Cisowski, and A. Volozhin, "Optical properties of new aliphatic-aromatic co-polyimides," Journal of Non-Crystalline Solids, vol. 299-302, no. 2, pp. 1057-1061, 2002.

[5] B. Hajduk, J. Weszka, V. Cozan, B. Kaczmarczyk, B. Jarzabek, and M. Domanski, "Optical properties of polyazomethine with oxygen atom in the backbon," Archives of Materials Science and Engineering, vol. 32, no. 2, pp. 85-88, 2008.

[6] R. H. Friend, "Conjugated polymers. New materials for optoelectronic devices," Pure and Applied Chemistry, vol. 73, no. 3, pp. 425-430, 2001.

[7] D. Sek, A. Iwan, B. Jarzabek et al., "Characterization and optical properties of oligoazomethines with triphenylamine moieties exhibiting blue, blue-green and green light," Spectrochimica Acta A, vol. 72, no. 1, pp. 1-10, 2009.

[8] A. Cihaner and F. Algi, "Electrochemical and optical properties of an azo dye based conducting copolymer," Turkish Journal of Chemistry, vol. 33, no. 6, pp. 759-767, 2009.

[9] N. Dubey and M. Leclerc, "Conducting polymers: efficient thermoelectric materials," Journal of Polymer Science B, vol. 49, no. 7, pp. 467-475, 2011. 
[10] A. C. Sparavigna, L. Florio, J. Avloni, and A. Henn, "Polypyrrole coated PET fabrics for thermal applications," Materials Sciences and Applications, vol. 1, pp. 253-259, 2011.

[11] T. Agostinelli, T. A. M. Ferenczi, E. Pires et al., "The role of alkane dithiols in controlling polymer crystallization in small band gap polymer: fullerene solar sells," Journal of Polymer Science B, vol. 49, no. 10, pp. 717-724, 2011.

[12] N. C. Miller, R. Gysel, C. E. Miller et al., "The phase behavior of a polymer-fullerene bulk heterojunction system that contains bimolecular crystals," Journal of Polymer Science B, vol. 49, no. 7, pp. 499-503, 2011.

[13] P. Yang, M. Lü, D. Xü et al., "Strong green luminescence of $\mathrm{Ni}^{2+}$-doped ZnS nanocrystals," Applied Physics A, vol. 74, no. 2, pp. 257-259, 2002.

[14] Y. Hattori, T. Isobe, H. Takahashi, and S. Itoh, "Luminescent properties of $\mathrm{ZnS}: \mathrm{Mn}^{2+}$ nanocrystals $/ \mathrm{SiO}_{2}$ hybrid phosphor synthesized by in situ surface modification co-precipitation," Journal of Luminescence, vol. 113, no. 1-2, pp. 69-78, 2005.

[15] P. Yang, M. Lü, D. Xu et al., "Luminescence characteristics of $\mathrm{ZnS}$ nanoparticles co-doped with $\mathrm{Ni}^{2+}$ and $\mathrm{Mn}^{2+}$," Optical Materials, vol. 24, no. 3, pp. 497-502, 2003.

[16] H. Soni, M. Chawda, and D. Bodas, "Electrical and optical characteristics of Ni doped ZnS clusters," Materials Letters, vol. 63, no. 9-10, pp. 767-769, 2009.

[17] R. Sharma, H. S. Bhatti, and K. Kyhm, "Enhanced oscillator strengths and optical parameters of doped $\mathrm{ZnS}$ bulk and nanophosphors," Applied Physics B, vol. 97, no. 1, pp. 145-155, 2009.

[18] C. M. Huang, L. C. Chen, G. T. Pan, T. C. K. Yang, W. S. Chang, and K. W. Cheng, "Effect of Ni on the growth and photoelectrochemical properties of $\mathrm{ZnS}$ thin films," Materials Chemistry and Physics, vol. 117, no. 1, pp. 156-162, 2009.

[19] H. R. Pouretedal, A. Norozi, M. H. Keshavarz, and A. Semnani, "Nanoparticles of zinc sulfide doped with manganese, nickel and copper as nanophotocatalyst in the degradation of organic dyes," Journal of Hazardous Materials, vol. 162, no. 2-3, pp. 674-681, 2009.

[20] N. S. A. Sharif, N. S. Ridhuan, Z. A. Ahmad, and S. D. Hutagalung, "Structural analysis of zinc sulphide nanopartiles synthesized via wet chemical route," Solid State Science and Technology, vol. 18, no. 1, pp. 91-95, 2010.

[21] L. Wang, X. T. Tao, J. X. Yang, Y. Ren, Z. Liu, and M. H. Jiang, "Preparation and characterization of the $\mathrm{ZnS}$ nanospheres with narrow size distribution," Optical Materials, vol. 28, no. 8-9, pp. 1080-1083, 2006.

[22] R. Maity, U. N. Maiti, M. K. Mitra, and K. K. Chattopadhyay, "Synthesis and optical characterization of polymer-capped nanocrystalline ZnS thin films by chemical process," Physica E, vol. 33, no. 1, pp. 104-109, 2006.

[23] G. Ghosh, M. Kanti Naskar, A. Patra, and M. Chatterjee, "Synthesis and characterization of PVP-encapsulated ZnS nanoparticles," Optical Materials, vol. 28, no. 8-9, pp. 10471053, 2006.

[24] S. K. Panda, A. Datta, and S. Chaudhuri, "Nearly monodispersed ZnS nanospheres: synthesis and optical properties," Chemical Physics Letters, vol. 440, no. 4-6, pp. 235-238, 2007.

[25] M. Pattabi, B. Saraswathi Amma, K. Manzoor, and Ganesh Sanjeev, "Effect of $8 \mathrm{MeV}$ electron irradiation on the optical properties of PVP capped CdS nanoparticles in PVA matrix," Solar Energy Materials and Solar Cells, vol. 91, no. 15-16, pp. 1403-1407, 2007.

[26] G. Murugadoss, "Synthesis and optical characterization of PVP and SHMP-encapsulated $\mathrm{Mn}^{2+} \mathrm{ZnS}$ nanocrystals," Journal of Luminescence, vol. 130, no. 11, pp. 2207-2214, 2010.
[27] K. Manzoor, S. R. Vadera, N. Kumar, and T. R. N. Kutty, "Synthesis and photoluminescent properties of $\mathrm{ZnS}$ nanocrystals doped with copper and halogen," Materials Chemistry and Physics, vol. 82, no. 3, pp. 718-725, 2003.

[28] G. Murugadoss, B. Rajamannan, and V. Ramasamy, "Synthesis and photoluminescence study of PVA-capped $\mathrm{ZnS}: \mathrm{Mn}^{2+}$ nanoparticles," Digest Journal of Nanomaterials and Biostructures, vol. 5, no. 2, pp. 339-345, 2010.

[29] L. Levy, J. F. Hochepied, and M. P. Pileni, "Control of the size and composition of three dimensionally diluted magnetic semiconductor clusters," Journal of Physical Chemistry, vol. 100, no. 47, pp. 18322-18326, 1996.

[30] A. Twardowski, T. Dietl, and M. Demianiuk, "The study of the s-d type exchange interaction in Zn1-xMnxSe mixed crystals," Solid State Communications, vol. 48, no. 10, pp. 845-848, 1983.

[31] K. Manzoor, S. R. Vadera, N. Kumar, and T. R. N. Kutty, "Energy transfer from organic surface adsorbate-polyvinyl pyrrolidone molecules to luminescent centers in $\mathrm{ZnS}$ nanocrystals," Solid State Communications, vol. 129, no. 7, pp. 469-473, 2004.

[32] G. Dong, X. Li, Z. Wei, S. Yang, and G. Fu, "Measurement of the time-resolved spectrum of photoelectrons from $\mathrm{ZnS}: \mathrm{Mn}$, Cu luminescent material," Journal of Physics Condensed Matter, vol. 15, no. 9, pp. 1495-1503, 2003. 

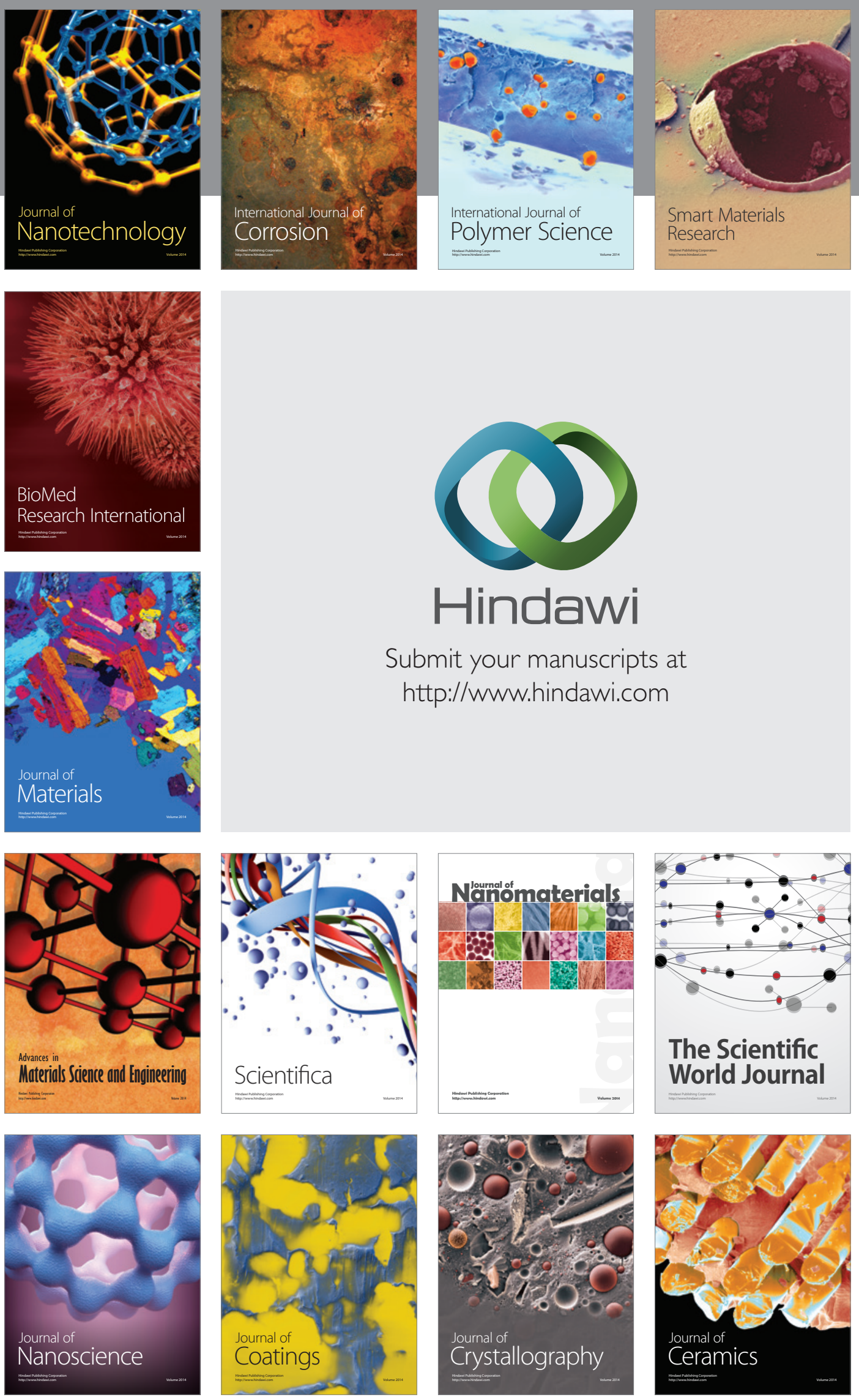

The Scientific World Journal

Submit your manuscripts at

http://www.hindawi.com

\section{World Journal}

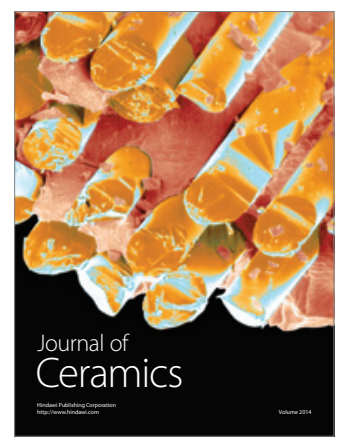

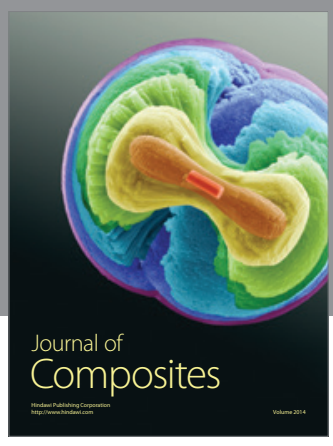
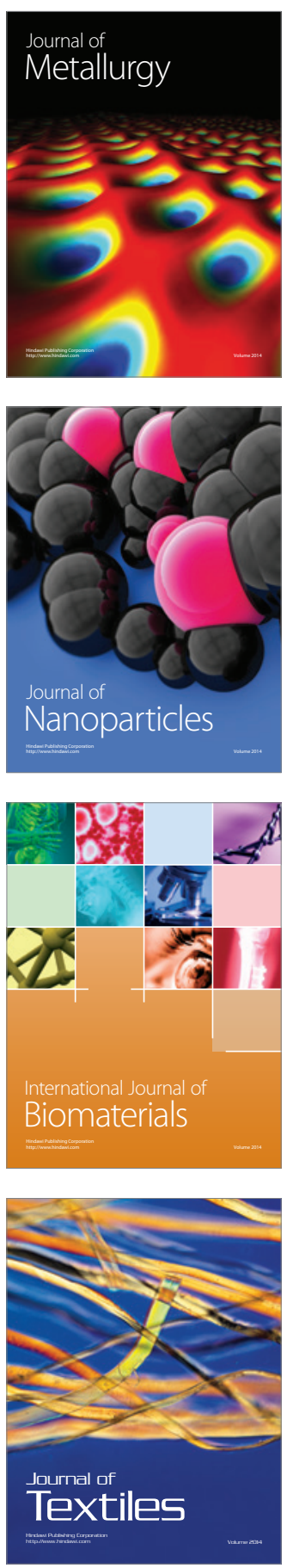